\title{
On Maurício M. Peixoto and the arrival of Structural Stability to Rio de Janeiro, 1955
}

\author{
JORGE SOTOMAYOR
}

\begin{abstract}
This essay is a historical exploration of the circumstances, and subsequent mathematical consequences, of the encounter, in 1955, of Maurício M. Peixoto (1921 - 2019) with the work of Henry F. DeBaggis (1916 - 2002) on Structural Stability, Princeton 1952 , developing a notion introduced by Alexander A. Andronov and Lev S. Pontrjagin, Gorkii 1937.

Key words: Andronov, DeBaggis, Lefschetz, Peixoto, Structural Stability, Differential Equations.

Mathematical Subject Classification: 01A60, 01A67, 37C20.
\end{abstract}

\section{AN ACCIDENTAL LIBRARY ENCOUNTER}

At the quiet Library of the Institute of Pure and Applied Mathematics (IMPA), in his after coffee afternoon browsing books routine, Mauricio $M$. Peixoto (Peixoto) stumbled on the article by H. F. DeBaggis (DeBaggis) entitled Dynamical Systems with Stable Structure, DeBaggis 1952, which captured his interest.

He read attentively the following phrases:

"...For physical systems to perform certain operations they must, if they are to be useful, possess a certain degree of stability. Small perturbations should not affect the essential features of the system.

Since the physical components of a system can never be duplicated exactly, experimental verification would be impossible unless the system remains stable under small variations.

The stability requirements of experiments provide a clue to the restrictions a mathematician should place on his nonlinear problems."

As an engineer, self taught mathematician and full professor of Rational Mechanics, with much higher than average knowledge of the differential equations of Classical Mechanics, Peixoto immediately noticed that a clever form of stability - or continuity - was involved in the author's text. It was Structural Stability.

He glimpsed at the references and there he found the book Theory of Oscillations, Andronov and Chaikin 1949, in the English Princeton translation of Andronov and Chaikin 1937. He had perused it in 1951 when writing his Thesis The General Equations of Mechanics, Peixoto 1951, presented in the competition for the Chair of Rational Mechanics at the University of Brazil. The book is cited in the chapter Stability, of the Thesis, which deals with the stability of stationary states, in the sense of Lyapunov, concerning initial data, and not in that of the 
phase space depending, as a whole, on the analytic data defining the system.

On 1951, however, the notion of Structural Stability, as mentioned along the Andronov and Chaikin book, did not attract his attention. The results by Andronov and Pontrjagin 1937, stating a characterization of Structurally Stable Systems in a planar region, whose border they cross transversally, was formulated on an appendix of Andronov and Chaikin 1949. No proofs were provided. This omission might have contributed to diminish the potential attractiveness of Structural Stability for many mathematically inclined readers in the West. Two exceptions - DeBaggis and Lefschetz - will be addressed below.

Complementing the phrases above, in a second reading round of DeBaggis 1952, Peixoto also glanced at:

"...In this paper we give a complete treatment of the theory of structural stability. We have relaxed the conditions of analyticity which were imposed on the functions by Andronov and Pontrjagin 1937 and merely require that they have continuous first partials."

He focused again on the concise list of references and attempted to grasp the structure of the paper examining the sections and the figures.

In the last browsing round he also looked at the short final remarks about bifurcations -the lost of structural stability- and the insinuation of a possible continuation in that direction in future work by the author.

Time had elapsed rapidly. Approaching the librarian desk for borrowing the journal, he whispered: This seems to be good stuff.

As he headed back home, carrying in his briefcase the article DeBaggis 1952, his thinking was accelerated. The encounter, apparently accidental, followed by the active browsing through it, had launched Peixoto's insightful mathematical intuition.

At home, he worked on the article until late hours. Afterwards he also discussed it with his wife Marília C. Peixoto (Marília), 1921 - 1961, also an engineer, mathematician and his assistant in the Chair of Mechanics.

They decided that, in due time, he should prepare a presentation on Structural Stability in the Seminar he directed, which had the participation of Marilia, selected students and teaching assistants of the Chair of Mechanics ${ }^{1}$.

During the preparation of the Seminar, confusing points in DeBaggis 1952 were detected, where corrections and essential improvements were foreseen. The idea of the handy introduction of a Functional space of Differential Equations, emerged. On it new results could be formulated in topological terms. This appears in the research note Peixoto 1955 published in September in that year, containing innovative results, such as the openness of structural stability.

During the next months, the project of a visit to Princeton to confer with Solomon Lefschetz, Editor of the Series Contributions to the Theory of Nonlinear Oscillations, began to be conceived.

\section{H. F. DEBAGGIS}

In 1949, on leave of absence form the University of Notre Dame at Princeton, Father Henry F. DeBaggis, CSC, browsing through the recently published book Andronov and Chaikin 1949, encountered the appendix on Structural Stability. He was looking for new horizons to go beyond Axiomatic Hyperbolic Geometry, field in which he had written a M.S. Dissertation and a PhD Thesis at Notre Dame.

\footnotetext{
${ }^{1}$ Mentioned in Peixoto's interview Eméritos III, 2011, https:/ /youtu.be/PToAegfcFKA.
} 
He decided to undertake the challenge of giving a proof of the Theorem of Andronov and Pontrjagin stated there. Though, at the beginning, he might not have had the suitable adroitness in Differential Equations and Classical Analysis, Solomon Lefschetz supported him. DeBaggis participated in Lefschetz' Research Project for two years. See quotation below. No additional information concerning DeBaggis' research in mathematics was found. In his Obituary one can read that he taught Mathematics in several North American Universities and also in other continents. No chronological data about him after he left Princeton was found.

\section{SOLOMON LEFSCHETZ, 1884 - 1972}

We quote from Griffiths, Spencer and Whitehead 1992:

"In 1943 Lefschetz became a consultant for the U.S. Navy at the David Taylor Model Basin near Washington, D.C. There he met and worked with Nicholas Minorsky, who was a specialist on guidance systems and the stability of ships and who brought to Lefschetz' attention the importance of the applications of the geometric theory of ordinary differential equations to control theory and nonlinear mechanics.

From 1943 to the end of his life, Lefschetz' main interest was centered around ordinary nonlinear differential equations and their application to controls and the structural stabilities of systems.

Lefschetz was almost sixty years old when he turned to differential equations, yet he did original work and stimulated research in this field as a gifted scientific administrator."

We quote from Lefschetz 1959, p. 1:
"During most of World War II, the undersigned, a consultant at the David Taylor Model Basin, had frequent interviews with Dr. Nicolas Minorsky, in connection with the latter's production of his well known Introduction to Nonlinear Mechanics.

Dr. Minorsky voiced repeated regrets at the impossibility of creating in this country anything resembling the well known Institute of Oscillations of Moscow, with its large staff of highly competent mathematicians and physicists devoted to the problems of oscillations and more generally to nonlinear mechanics (equally called nonlinear differential equations).

We quote from Lefschetz 1959, p. 15:

"Father Henry DeBaggis, an Assistant Professor of Mathematics at Notre Dame and a PhD. under Karl Menger at Notre Dame also, joined our Project in 1949 and was a member for two years 1949 - 51.

While his thesis was on Hyperbolic Geometry, he had little taste for that subject and wished to change over to Differential Equations.

A reading of an appendix in Andronov and Chaikin 1949 recently appeared, awoke his interest in structural stability.

This highly interesting concept had been launched in a Note of the Doklady in Andronov and Pontrjagin 1937. They considered a planar system defined in a closed two-cell with vectors pointing outwards along the boundary and asked under what conditions does the topology of the system of paths remain unchanged for small variations of the vector field throughout the two-cell.

They stated n.a.s.c. for this to happen but gave no proofs. 


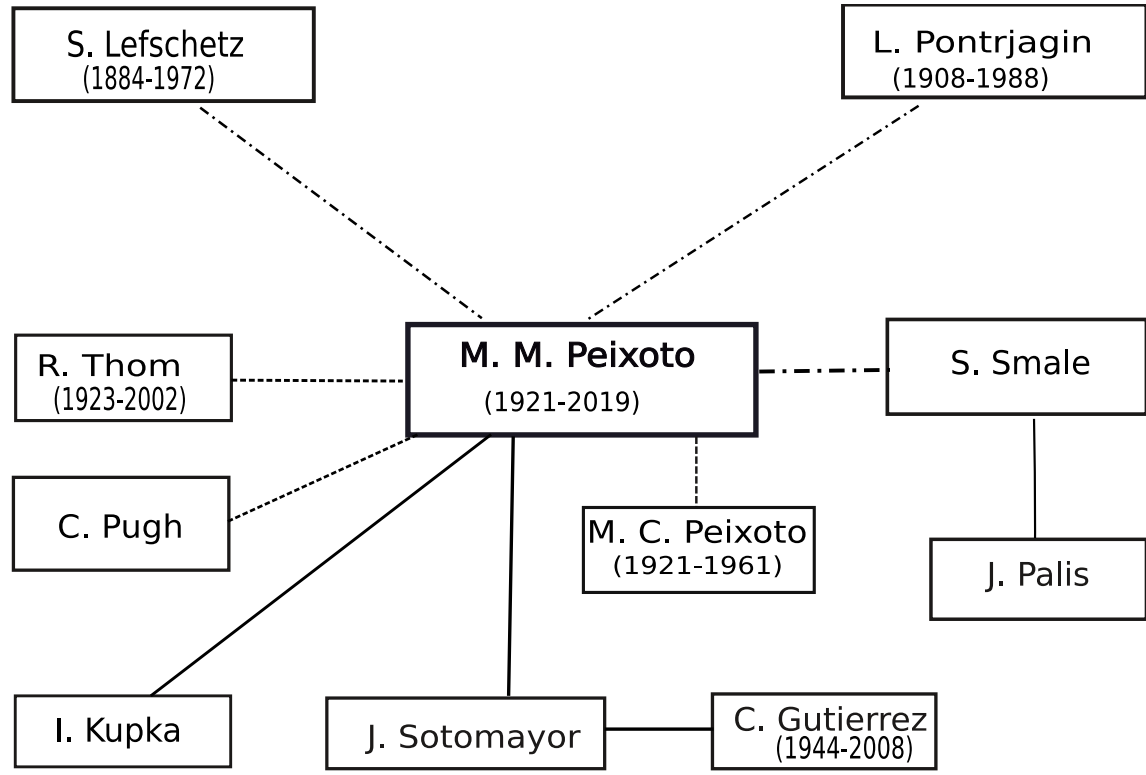

Figure 1. Mathematical contacts and influences mentioned by Peixoto in his charming Acceptance Speech on the occasion of the TWAS Mathematics Award in 1987, where he presented an outline of crucial developments in Dynamical Systems. See Peixoto 1987 and its Portuguese translation in Sotomayor, Garcia and Mello 2020.
DeBaggis undertook to establish a complete theory and this objective was attained. His results were developed in a paper which appeared in DeBaggis 1952 and was sub sequently translated into Russian DeBaggis 1955.

It is only fair to say that DeBaggis derived very great benefit from discussions with $M$. Schiffer, D. Spencer and the Director."

Lefschetz' interest on Structural Stability was notorious. Besides renaming it from "Roughness", he had addressed to Andronov a letter suggesting that "a theorem of such importance should have its proof published." Unpublished correspondence exhibited in a glass display case, together with manuscripts and books of Andronov, at the Meeting in commemoration of his $100^{\text {th }}$ anniversary, Andronov 2002.

\section{THE LETTER OF PEIXOTO TO LEFSCHETZ, 1956}

Peixoto proposed to establish that the systems defined by the conditions of Andronov and Pontrjagin form an open and dense set inside the open set of vector fields transversal to the border of the region supporting the system.

Upon reception of the letter, Lefschetz became deeply interested in Peixoto's project. He promptly wrote him back and suggested how to proceed to apply for a Research Associate visiting position at Princeton.

With the support of CNPq he visited Princeton during the academic year 1957 - 58, continuing further in RIAS, Baltimore, during 1958-59.

This interesting stage of Peixoto mathematical activities, The Golden Years, in which he met Stephen Smale, are recounted in his charming Speech of Acceptance of the TWAS Mathematics Award, 1987. See Peixoto 1989 and Sotomayor, Garcia and Mello 2020.

\section{A MEANING FOR AN ACCIDENTAL ENCOUNTER}

In 1943 the eminent mathematician Solomon Lefschetz: algebraic geometer and topologist, reaching his sixties, decided to change his research interests and started to work in Differential Equations. This happened after 
encounters he had with the Naval Engineer Nicholas Minorsky, an "ingeniéur savant", Petitgirard 2015. See also the quotation above to Lefschetz about Minorsky.

From Princeton Lefschetz launched several editorial activities to spread the interest on Nonlinear Differential Equations, Lefschetz 1959. One of them was the Edition of the Series Contributions to Nonlinear Oscillations, which in Vol. II published the paper DeBaggis 1952. In 1955 it reached Peixoto in Rio de Janeiro and, after substantial elaboration, took him to Princeton to have the benefit of The Golden Years of his mathematical career. See Peixoto 1987 and Sotomayor, Garcia and Mello 2020.

On the afternoon of the encounter of Peixoto with DeBaggis paper, a narrow cosmic fracture allowed a considerable amount of repressed mathematical energy to flow into the library of IMPA. It was liberated by the apparently accidental and seemingly naive ceremony of browsing through a mathematics article, as a dam under pressure releases its flow through a fissure. On the right side of the dam to channel the flow, there was a receptive, insightful and sensitive mind. One that was prepared for the challenge and could grasp the complexity of the inflowing mathematical message.

Thus, Structural Stability, carrying its rich heritage and mathematical background, arrived from Gorkii, now Nizhnii Novgorod, to Rio de Janeiro, then the Capital of Brazil, after an auspicious maturation in Princeton, one of the capitals of World Mathematics.

\section{CONTACTS AND INFLUENCES OF PEIXOTO AROUND PRINCETON 1958, TWAS 1987 AND AFTER}

Aspects of Peixoto's mathematical biography, including also an outline of his preponderance in the Brazilian scientific scenario, can be found in Sotomayor, Garcia and Mello 2020, Sotomayor 2019, Sotomayor 2018 and Sotomayor 2001.

\section{Acknowledgments}

The author is grateful to J. Derwent and to $\mathrm{H}$. Weiss for their valuable help to get access to, respectively, the works of DeBaggis in Notre Dame and the enlightening Lefschetz Report, Lefschetz 1959. Thanks are also due to D. Schlomiuk, M. Sotomayor, L. F. Mello, A. R. da Silva, R. A. Garcia and to an anonymous referee for their helpful comments to this text. Special thanks are due to R. A. Garcia for drawing the diagram in this paper. The author had the partial support of CNPq, PQ-SR - 307690/2016-4.

\section{REFERENCES}

ANDRONOV AA. 2002. Mathematical problems of nonlinear dynamics. Progress in nonlinear science. Vol. 1. Proceedings of the International Conference dedicated to the 10oth Anniversary of A. A. Andronov, Nizhny Novgorod, 2001. Lerman LM \& Shil'nikov LP (Eds), Russian Academy of Sciences and Institute of Applied Physics, Nizhniy Novgorod. $416 \mathrm{p}$.

ANDRONOV AA \& CHAIKIN SE. 1937. Theory of Oscillations (Russian), Moscow - Leningrad, ONTI, $520 \mathrm{p}$.

ANDRONOV AA \& CHAIKIN SE. 1949. Theory of Oscillations. In: Lefschetz S (Ed), (English version Ed), Princeton, Princeton University Press, $358 \mathrm{p}$.

ANDRONOV AA \& PONTRJAGIN LS. 1937. Robust systems (Russian). DAN 14(5): 247-250.

DEBAGGIS HF. 1952. Dynamical systems with stable structure. Contributions to the Theory of Nonlinear Oscillations II, Lefschetz S (Ed), Princeton, Princeton University Press: 37-59.

DEBAGGIS HF. 1955. Dynamical systems with stable structure (Russian). Uspekhi Mat Nauk 10, 4(66): 101-126.

GRIFFITHS P, SPENCER D \& WHITEHEAD G. 1992. Solomon Lefschetz, A biographical memoir. Nac Acad Sciences, Biographical Memoirs 16: 271-313.

LEFSCHETZ S. 1959. Final Report of the Project Director. Nonlinear Differential Equations and Nonlinear Oscillations, August 1946 September 1959. US Office of Naval Research, $71 \mathrm{p}$. 
PEIXOTO MM. 1951. Equações gerais da dinâmica. Rio de Janeiro, $110 \mathrm{p}$.

PEIXOTO MM. 1955. Note on structurally stable systems. An Acad Bras Cienc 27: 35.

PEIXOTO MM. 1989. Acceptance Speech, TWAS Award, 1987. In Proceedings of the Second Conference Organized by the TWAS. World Scientific, Singapore, p. 600-614.

PETITGIRARD L. 2015. L'ingénieur Nicolas Minorsky (1885- 1970) et les mathématiques pour l'ingénierie navale, la théorie du controle et les oscillations non linéaires. Revue d'histoire des math 21: 173-216.

SOTOMAYOR J. 2001. A few words about Maurício M. Peixoto on his $80^{\text {th }}$ birthday. In The Geometry of Differential Equations and Dynamical Systems, Volume Edited by SOTOMAYOR J. Computational and Applied Mathematics, 20: 1-2.

SOTOMAYOR J. 2018. Mathematical Encounters. Notices ICCM, 6, 2: $94-98$.

SOTOMAYOR J. 2019. On a list of problems of ordinary differential equations. SPJMS 13(1): 177-194.

SOTOMAYOR J, GARCIA R \& MELLO L. 2020. Maurício M. Peixoto (1921 - 2019). Revista Matemática Universitária, SBM, in print, 1: $1-22$.

\section{How to cite}

SOTOMAYOR J. 2020. On Maurício M. Peixoto and the arrival of Structural Stability to Rio de Janeiro, 1955. An Acad Bras Cienc 92: e20191219. DOI 10.1590/0001-3765202020191219.

Manuscript received on October 4, 2019; accepted for publication on December 30, 2019

\section{JORGE SOTOMAYOR}

https://orcid.org/0000-0003-2280-8652

Instituto de Matemática e Estatística, Universidade de São Paulo, Rua do Matão, 1010, 05508-09o São Paulo, SP, Brazil

E-mail:sotp@ime.usp.br

\section{(cc) BY}

